\title{
Urodimento
}

REVISTA DE ESTUDOS EM ARTES CÊNICAS

E-ISSN 2358.6958

\section{Artistas de Dioniso: Atores e músicos na tragédia grega antiga}

Vinicius Torres Machado

João Pedro Ferreira dos Santos Ribeiro

Para citar este artigo:

MACHADO, Vinicius Torres; RIBEIRO, João Pedro Ferreira dos Santos. Artistas de Dioniso: Atores e músicos na tragédia grega antiga. Urdimento - Revista de Estudos em Artes Cênicas, Florianópolis, v. 2, n. 41, set. 2021.

do) DOI: http:/dx.doi.org/10.5965/1414573102412021e0111

Este artigo passou pelo Plagiarism Detection Software | iThenticate 


\title{
Artistas de Dioniso: Atores e músicos na tragédia grega antiga
}

\author{
Vinicius Torres Machado ${ }^{1}$ \\ João Pedro Ferreira dos Santos Ribeiro²
}

\begin{abstract}
Resumo
Este artigo tem por objetivo analisar a posição ocupada por atores e músicos no sistema de produção da espetacularidade trágica grega antiga, dentro e fora da cena, no intervalo que vai do século $V$ a.C. ao século II a.C. Para tanto, foi proposta uma trajetória que parte da tragédia como uma atividade circunscrita às famílias da elite ateniense, passa pela emergência de um mercado de trabalho para atores, pela consolidação de um sistema de estrelato, até chegar na organização de associações dos artistas de Dioniso. Como representativas desse percurso, foram evocadas as imagens de Sófocles, Calípides, Neoptólemo e Cráton.
\end{abstract}

Palavras-chave: História do Teatro. Tragédia Grega. Ator. Músico.

\section{Artists of Dionysus: Actors and musicians in ancient Greek tragedy}

\begin{abstract}
This article aims to analyze the position occupied by actors and musicians in the production system of ancient Greek tragic spectacle, inside and outside the scene, in the interval between the 5th century BC and the 2nd century BC. For that, a trajectory was proposed that starts from tragedy as an activity limited to the families of the Athenian elite, passes through the emergence of a job market for actors, through the consolidation of a star system, until arriving at the organization of associations of artists of Dionysus. As representative of this path, the images of Sophocles, Kallipides, Neoptolemus and Kraton were evoked.
\end{abstract}

Keywords: History of Theater. Greek Tragedy. Actor. Musician.

${ }^{1}$ Doutorado em Artes Cênicas pela Universidade de São Paulo, com estágio supervisionado na Ghent University (Bélgica). Professor Doutor do Instituto de Artes da Universidade Estadual Paulista "Júlio de Mesquita Filho". vinicius.t.machado@unesp.br

9 https://orcid.org/0000-0002-9840-8789 (iD https://orcid.org/0000-0002-9840-8789

${ }^{2}$ Mestrando em Artes da Cena pelo Instituto de Artes da Universidade Estadual Paulista "Júlio de Mesquita Filho".jp.ribeiro@unesp.com

(6) https://orcid.org/0000-0001-6894-7450 (iD https://orcid.org/0000-0001-6894-7450 


\section{Artistas de Dioniso: Actores y músicos en la tragedia griega antigua}

\section{Resumen}

Este artículo tiene como objetivo analizar la posición ocupada por los actores y músicos en el sistema de producción del espectáculo trágico griego antiguo, dentro y fuera de la escena, en el intervalo entre el siglo V a.C. y el siglo II a.C. Para eso, se propuso una trayectoria que parte de la tragedia como actividad limitada a las familias de la élite ateniense, pasa por la emergencia de un mercado laboral para los actores, por la consolidación de un sistema de estrellato, hasta llegar a la organización de asociaciones de los artistas de Dioniso. Como representativas de ese camino, fueron evocadas las imágenes de Sófocles, Calípides, Neoptólemo y Cratón.

Palabras clave: Historia del Teatro. Tragedia Griega. Actor. Músico. 
Tendo em vista o esforço contemporâneo em reavaliar os estudos teatrais em função da teatralidade e da performatividade da cena, cumpre apontarmos novos direcionamentos para a compreensão do espetáculo da tragédia grega antiga. Há uma linha de pesquisa ${ }^{3}$, desenvolvida sobretudo a partir da segunda metade do século XX, que busca empreender essa tarefa por meio de uma análise bastante criteriosa de documentos históricos, não obstante à aplicação de alguns conceitos teatrais cunhados no contexto da contemporaneidade.

É interessante observarmos como os estudos teatrais podem influenciar a maneira como os estudos clássicos analisam os documentos históricos. Meineck (2013), por exemplo, evoca os conceitos de erupção e procissão, cunhados por Schechner (1988) para analisar a cena de As Eumênides, de Ésquilo:

O teórico da performance Richard Schechner descreve as primeiras formas de performance como "teatro natural" e o divide em duas categorias amplas: "erupções" e "procissões". Uma "erupção" é um evento estático que se desenrola em um local onde uma multidão se reúne para assistir, enquanto uma "procissão" tem uma rota predeterminada e um objetivo final fixo. Ele segue uma estrutura organizada e uma forma comumente compreendida. Portanto, as exibições visuais inerentes à procissão são importantes na comunicação de identidade, status e poder. Schechner descreve como a procissão tende a fazer várias paradas ao longo de seu percurso, onde ocorrem performances estacionárias associadas. Estas são "erupções" processionais e os espectadores podem se reunir para assistir, participar e/ou continuar a acompanhar a procissão até seu objetivo final (Meineck, 2013, p.168)4.

Abordagens como a de Meineck (2013), a partir da evocação de conceitos cunhados por Schechner (1988), nos ajudam a abandonar a ideia de que a tragédia grega antiga era realizada em enormes teatros de pedra, como o Teatro de Epidauro ou o Teatro de Dioniso, cujas estruturas preservadas datam do século IV

${ }^{3}$ Alinhados a ela, destacam-se, no Brasil, os trabalhos de Mota (2008), que investiga a dramaturgia musical na obra de Ésquilo, e de Ramos (2015), que propõe um diálogo entre conceitos cunhados no contexto da antiguidade clássica e conceitos da teoria teatral contemporânea.

${ }^{4}$ The performance theorist Richard Schechner describes early performance forms as "natural theatre" and divides this into two broad categories: "eruptions" and "processions." An "eruption" is a static event that unfolds in one location where a crowd gathers to watch, whereas a procession has a predetermined route and a fixed, final goal. It follows an organized structure and a commonly understood form. Hence, the visual displays inherent in the procession are important in communicating identity, status and power. Schechner describes how the procession has a tendency to make several stops along its route where associated stationary performances take place. These are processional "eruptions" and spectators can gather to watch, participate and/or continue to follow the procession to its ultimate goal. [Tradução nossa] 
a.C., mais de um século depois do período áureo da Grande Dionisíaca. Os documentos apontam que "os primeiros festivais para Dioniso provavelmente giravam em torno da participação em uma procissão que parava em pontos-chave da cidade e apresentava performances corais aos participantes que se reuniam para assistir" (Meineck, 2013, p.168)

Em vista dessa compreensão, cumpre reavaliarmos a tragédia grega antiga como um espetáculo cívico-ritual de canto e dança no seio de uma festividade pública. É nesse sentido que Wilson (2005) nos conta que se parássemos um ateniense médio do século $\vee$ a.C. em seu caminho para uma apresentação de tragédias na Grande Dionisíaca e perguntássemos para onde estava indo, muito provavelmente teríamos como resposta: "es chorous" ("aos coros") ou "es tragoidós" ("aos cantores trágicos")6. E se questionado como categorizava essa atividade tão importante para sua cidade, certamente empregaria o termo "mousikế" ("ofício das Musas"), que deu origem ao nosso "música". De modo que Wilson (2008) argumenta:

O teatro grego antigo era fundamentalmente uma experiência musical. Se suas origens remontam quer às canções para dançar dos cultos realizados em honra de Dioniso, quer a mascaradas rituais feitas pelos companheiros do deus, quer ainda a celebrações informais nas vindimas ou em algum importante sacrifício, o fato é que um componente essencial da primeira matriz do drama era a música (Wilson, 2008, p.45).

Podemos compreender a música como elemento aglutinador do espetáculo da tragédia grega antiga. Poetas, atores, coreutas e instrumentistas tinham como ponto de conexão de suas práticas o elemento musical, cuja expressão mais ilustrativa talvez seja a performance do coro, um grupo de doze a quinze homens que cantavam e dançavam no centro do espaço cênico: "pelo menos até a metade do século V a.C., a tragédia girava em torno de seu coração cantante e dançante, o coro" (Wilson, 2005, p.183) .

${ }^{5}$ early festivals to Dionysos likely revolved around participation in a procession which would halt at key points in the city and present choral performances to processional participants who gathered to watch. [Tradução nossa]

6 Tragoidós é a palavra grega padrão para "poeta trágico", "ator trágico", ou "coreuta trágico".

${ }^{7}$ at least until the middle of the fifth century, tragedy was oriented around its singing-and-dancing heart, the chorus. [Tradução nossa] 
Não obstante, apesar de a imagem do coro nos ajudar a perceber a centralidade da música no espetáculo trágico grego antigo, devemos considerar que esta não se restringia aos momentos de performance coral. É a partir dessa compreensão que Hall (2008) propõe uma reavaliação da profissão do ator antigo por meio do resgate da história dos atores-cantores, de modo a evidenciar a indissociabilidade entre as artes de representar e de cantar no mundo pagão greco-romano. A afirmação de Herington (1985) de que "os trágicos parecem como inseparáveis de uma cultura da canção" (Herington, 1985, p.10) ${ }^{8}$, serve de base para que Hall (2008) desenvolva o argumento segundo o qual:

Os atenienses conheciam muitos cantos de cor: hinos, cantos de congratulações a atletas e militares vitoriosos, de procissões, báquicos, de trabalho, acalantos, encantamentos médicos e mágicos, bem como cantos para indicar galanteio, casamento, nascimento ou morte. [...] Muitos cantos na tragédia [...] são derivados de um dos gêneros preexistentes de canto "ritual" ou de "atividade" e estão no metro lírico a eles apropriados (Hall, 2008, p.6-7).

Segundo Hall (2008), "a inovação da tragédia consistiu em integrar gêneros num padrão artístico complexo" (Hall, 2008, p.7), isto é, em função da demanda da cena. Wilson (2005) explica que o coro, na maioria das vezes, entrava no espaço cênico cantando e marchando em uníssono no início do espetáculo, naquilo que se denomina parodos; e da mesma forma saía no final, no exodos. Geralmente, intercalados com os episódios do drama, havia três ou quatro passagens de canto e dança corais, os stasima. O coro também se envolvia em trocas cantadas com os atores, denominadas kommos. E os atores também cantavam, bem como transitavam entre a fala e o canto. Versos em anapesto semi-cantados, por exemplo, eram utilizados em momentos em que o drama exigia alta tensão emocional. Até mesmo versos em trímetro iâmbico, que têm uma cadência mais próxima da fala comum, eram bastante ritmados. Havia, finalmente, interlúdios puramente instrumentais, talvez nada mais do que breves floreios entre as estrofes de canto coral, denominadas mesaulia ou diaulia.

Cumpre notar, no entanto, que "em termos de estruturas melódicas, timbre,

${ }^{8}$ the tragedians appear as an inseparable song culture [Tradução nossa] 
estilos de performance e até ritmos, a música da tragédia é um mundo perdido" (Wilson, 2005, p.186) ${ }^{9}$. Wilson (2005) pontua que talvez a base mais sólida, ainda que com muitas peças faltando, que temos para pensar como era música na tragédia grega antiga são os modos, um conjunto de notas e intervalos que carregava associações muito poderosas com o contexto extra teatral em que surgiram. Os modos, em geral, tinham nomes que se relacionavam ao grupo étnico do qual se originaram: dórico, lídio, jônico, frígio etc. De modo que Hall (2008) sugere que ao observarmos esse modelo, "é possível, de um ângulo sociológico, considerar a apropriação pela tragédia, de metros [e modos] ${ }^{10}$ associados a outros lugares como um imperialismo cultural ateniense manifestado no nível da forma" (Hall, 2008, p.8).

Era, portanto, necessário um instrumento especialmente adaptável a todas essas variações musicais exigidas pelo espetáculo da tragédia grega antiga. Segundo Wilson (2008), as fontes indicam com unanimidade que esse instrumento era o aulós ou, mais apropriadamente, os auloi, no plural, uma vez que essas flautas com furos para os dedos e palheta para boca era tocada sempre aos pares por um único instrumentista, o auletés. O som penetrante dos auloi era a base para todos os gêneros de apresentações dionisíacas, não apenas as tragédias, mas também os ditirambos, os dramas satíricos e as comédias e, mais do que isso, também era ouvido em muitas outras funções sociais, ao que Wilson (2008) complementa: "seu uso e familiaridade [...] com ecos de melodias tradicionalmente tocadas em tais funções, devem ter influenciado sua percepção no drama" (Wilson, 2008, p. 48). O som dos auloi eram tanto uma constante em rituais de sacrifício e em contextos de luto e lamentação, tais quais funerais, quanto em contextos de celebração e diversão, tais quais casamentos e simpósios.

Uma vez que as apresentações teatrais eram realizadas ao ar livre, exigia-se do instrumentista movimentos grandiloquentes e o volume máximo de emissão de som. Portanto, para assegurar um firme controle oral dos auloi, Wilson (2008) explica que o aule tés teatral utilizava um equipamento denominado phorbeiá:

\footnotetext{
${ }^{9}$ in terms of melodic structures, timbre, performance styles, and even rhythms, the music of tragedy is a largely lost world [Tradução nossa]

10 [Adição nossa]
} 
"uma série de tiras de couro ou 'cabrestos' que, geralmente passavam em volta das bochechas e sobre a cabeça dos instrumentistas, e a boca era perfurada para acomodar os bocais da flauta" (Wilson, 2008, p.52). Essa imagem pode nos ajudar a compreender porque, apesar da tragédia, seus poetas e seus coreutas gozarem de grande prestígio social na Atenas do século $\vee$ a.C., o mesmo não acontecia com o aule tés:

Em especial o aulós veio a ser associado - em parte por causa de sua aura intensamente dionisíaca - com a perda do controle e, mais particularmente, com a perda do discurso articulado. O instrumento que bloqueava a boca, e assim impedia o uso de lógoi, tendia a ser problemático numa cidade que tanto se orgulhava do papel proeminente e da qualidade de seu discurso (Wilson, 2008. p.52-53).

Assim sendo, apesar de Atenas requerer muitos tocadores de aulós, estes eram, em sua maioria, atenienses de estratos sociais muito baixos ou estrangeiros. Evidências indicam, por exemplo, que havia muitos escravos tocadores de aulós, muito embora não saibamos se estes se apresentavam em festivais de teatro. 0 mais corroborável é que a maioria dos auletai que se apresentavam em festivais de teatro no século $V$ a.C. viessem da fronteira com a Beócia, região cujo patrono era Dioniso. Estes, muito provavelmente, eram pagos por seus serviços e nunca houve, pelo que indicam as fontes, qualquer prêmio para os aulettai dionisíacos como competidores. Isso, de certa maneira, os colocava fora do sistema de reconhecimento do espetáculo trágico grego antigo, de modo que Wilson (2008) argumenta que "eles provavelmente eram considerados como reles recebedores de um 'salário', mas não como competidores ativos por prêmios e prestígio" (Wilson, 2008, p.60). Artistas remunerados por sua atividade profissional, em geral, não eram tidos em boa consideração pelos atenienses, que os excluía do círculo de cidadãos competentes para concorrer em uma festividade.

Essa diferença social entre os atenienses e os auletai manifestava-se também na própria cena. Estes não integravam a ação dramática, apesar de sua performance ser intrínseca ao espetáculo. Nesse sentido, Kovacs (2013) argumenta que as fontes, em sua maioria, retratam-nos agachados, em uma posição diferente daquela em que eram retratados os personagens, mas teatralmente vestidos, visíveis aos espectadores. Eles integravam a cena, mas não o drama. 
Muito embora o aulós fosse o instrumento musical da tragédia grega antiga por excelência, cumpre notar também, a partir de muitas representações iconográficas da época, a presença da lira em cena. Os tocadores de lira, no entanto, eram representados em uma posição muito diferente dos aulêtai.

Segundo Kovacs (2013), as fontes indicam que a lira em formato de concha fabricada com o casco de tartarugas, a chelys, era utilizada como um adereço de cena manipulado pelos próprios atores, enquanto era acompanhada pela lira em formato de caixa, a kithara, manipulada de fora do espaço cênico por um profissional. Podemos justificá-lo a partir da compreensão de que a chelys era um instrumento tradicional e mitológico, compatível com o universo mítico e heróico dos personagens do drama, mas com um volume muito baixo, ao passo que a kithara era um instrumento com mais volume, compatível com as demandas do espetáculo. Além disso, mesmo que os atores possuíssem a habilidade técnica para tocar instrumentos de corda, eles teriam enfrentado obstáculos significativos para tocar durante sua performance, como, por exemplo, o uso de máscaras.

Se destacamos até aqui a performance musical do coro, dos atores e dos instrumentistas, cumpre apontar que os poetas trágicos também deveriam ser versados em matéria de música. Em primeiro lugar, porque eles mesmos compunham as músicas para seus espetáculos. Em segundo lugar, porque evidências sustentam que os primeiros poetas trágicos eram também atores de suas peças. Sobre o que Hall (2008) pontua:

Especula-se que Sófocles tenha desistido de atuar em suas próprias peças em virtude de sua voz fraca [...]. Diz-se também que Sófocles levava em consideração os talentos de seus atores ao compor seus papeis [...], e que as habilidades vocais dos atores principais disponíveis [...] devem ter influenciado todos os trágicos. (Hall, 2008, p.11)

E Kovacs (2013) complementa, em citando o Deipnosofistas, de Ateneu:

Sófocles, além de belo em sua juventude, também aprendeu dança e música quando ainda era criança, com Lampros. Depois da batalha naval de Salamina, ele, nu e com óleo, dançou com uma lira em volta do monumento. Alguns dizem que ele estava vestido. Ele mesmo tocou lira quando produziu Thamyris [...]. (Ateneu apud Kovacs, 2013, p.495) ${ }^{11}$

${ }^{11}$ Sophocles, in addition to being good looking in his youth, was also taught dancing and music while still a 
Segundo Kovacs (2013), esse trecho deve ser compreendido como uma anedota que representa a estatura heroica do poeta; sem embargo, a referência ao Thamyris parece verossímil. Na mitologia grega antiga, Tâmiris era um tocador de kithara conhecido por ter desafiado as Musas e, como retaliação, perdeu a visão. Sófocles teria retratado esse tema em uma tragédia e, apesar das evidências apontarem que ele tenha desistido de atuar em suas próprias peças em virtude de sua voz fraca, parece fazer sentido que ele tenha tocado kithara na apresentação de Thamyris. Sófocles, muito provavelmente, aprendeu a tocar lira em sua infância, visto tratar-se esta de uma habilidade essencial na educação dos cidadãos atenienses. Além disso, ele mesmo havia composto a música e executála certamente reduziria os custos da apresentação.

Se é possível associarmos a formação musical de Sófocles a uma educação tão cara à elite ateniense, devemos considerar que, assim como ele, todos os primeiros poetas e atores trágicos compartilhavam essa linhagem. Sutton (2016) realiza um estudo genealógico muito cuidadoso a fim de evidenciar que o teatro do início do século $\vee$ a.C. foi dominado por clãs que eram, na maior parte dos casos, compostos por famílias atenienses. No tempo dos primeiros poetas e atores, o teatro era uma atividade familiar e a formação de novos artistas estava relacionada à educação dos jovens meninos, realizada fundamentalmente dentro de casa. Segundo Csapo (2010), uma vez que os primeiros poetas representavam eles mesmos os protagonistas de seus dramas e thes cabia escolher quem representaria os deuteragonistas e os tritagonistas, na prática, isto significava contratar os próprios filhos e sobrinhos ou os filhos e sobrinhos de outros poetas. Em vista disso:

Por exemplo, nada menos do que onze poetas e atores trágicos conhecidos são descendentes diretos do pai de Ésquilo, Euforião; nada menos do que quatro poetas e atores trágicos conhecidos são descendentes do pai de Sófocles, Sófilos; nada menos que nove poetas e atores trágicos conhecidos são descendentes do pai de Carcino, Xenótimo; Eurípides teve pelo menos um filho que era um ator trágico [...]. (Csapo, 2010, p.88)

child by Lamprus. After the sea battle at Salamis he, naked and oiled, danced to the lyra about the monument. Others say he was dressed. He himself played the lyra when he produced Thamyris; further, he played ball exceedingly well, when he played Nausicaa. [Tradução nossa]

${ }^{12}$ For example, no less than eleven known tragic poets and tragic actors are direct offspring of Aeschylus' father, Euphorion; no less than four tragic poets and actors are known offspring of Sophocles' father, 
Perceber essa organização familiar como fundamento do sistema de produção da espetacularidade trágica grega na primeira metade do século $V$ a.C., nos ajuda a compreender a posição ocupada, dentro e fora da cena pelos auletai. Aos artistas remunerados, em geral, não cabia o gozo do prestígio.

Essa situação somente começou a ser desafiada quando os atores passaram também a integrar uma categoria identificável de profissionais no mundo grego antigo. Um acontecimento emblemático que pode nos auxiliar na compreensão desse processo é a instituição do prêmio para o melhor ator na Grande Dionisíaca de 449 a.C. Segundo Easterling (2008), esse fato corrobora com o argumento de que, mesmo usando máscaras que cobriam completamente seus rostos e interpretando mais de um papel em um mesmo espetáculo, os atores eram identificáveis pelo público e causavam enorme impacto por meio de suas vozes. A possibilidade de receber prêmios em dinheiro associada ao apelo carismático de suas performances contribuiu para que no final do século $\vee$ a.C. e no início do século IV a.C. os atores experienciassem um aumento do seu poder de ganho e do seu prestígio que culminaram na sua profissionalização.

É válido notar, no entanto, que os ecos dessa profissionalização carregam a dubiedade que acompanhará a imagem do ator nos anos seguintes. Nesse sentido, Csapo (2010) argumenta que se por um lado a institucionalização do prêmio oferece reconhecimento oficial aos atores, por outro, demarca também oficialmente a divisão que isolava os atores dos coreutas e dos poetas e, em última instância, do conjunto do espetáculo, que concorria ao prêmio principal.

Assim sendo, intensifica-se entre o final do século $V$ a.C. e o início do século IV a.C. uma tensão entre os novos atores profissionais e as famílias atenienses detentora do conhecimento teatral. Esta se ressentia por assistir a um grupo de pessoas, de origem muitas vezes humilde, adquirir riqueza e glória por meio de uma atividade que até então era dominada por famílias ricas atenienses. Desta feita, Csapo (2010) aponta que, ironicamente, a evidência mais segura que temos para atestar o processo de profissionalização dos atores é, provavelmente, o histórico de desprezos que a elite dirigia a eles, preservado em documentos que 
datam de 420 a.C em diante.

Se os primeiros atores trágicos gregos antigos eram pouco referenciados, da hostilização por parte da elite derivaram tantas informações sobre atores do final do século $V$ a.C., como Calípides, quanto de qualquer um dos grandes ícones da atuação do século IV a.C. Csapo (2010) indica, por exemplo, que há muitas anedotas preservadas que enfatizam a pomposidade, a incompetência e a vulgaridade de Calípides. Embora a maioria delas conste em fontes datadas da antiguidade posterior, podemos considerar que a tendência de ridicularizar Calípides é também contemporânea à sua atividade como ator.

Uma dessas anedotas pode ser encontrada na Poética de Aristóteles, quando este afirma que "Minisco chamava a Calípides macaco, porque ele era muito exagerado" (Aristóteles, 2008, p.104). Csapo (2008) argumenta que apesar de essa anedota não possuir valor histórico, ela ilustra como a geração de atores do final do século $\vee$ a.C. era vista pelos atores mais velhos. A expressão "porque ele era muito exagerado" pode ter duas interpretações: a primeira diz respeito a gestos exagerados, estilizados em excesso, ao passo que a segunda a um exagero de gestos, mimetizados em excesso. Segundo Csapo (2008), a segunda é mais acertada: tanto no contexto da narrativa, quando a crítica é proferida por Minisco, quanto no contexto da narração, quando a crítica é proferida por Aristóteles, ela recai sobre o fato de Calípides imitar tudo. "Calípides produz gestos que as sensibilidades não-vulgares prefeririam não ver na tragédia, especificamente gestos da não-elite" (Csapo, 2008, p.147). A atuação de Calipides introduz na cena uma tensão entre a representação do herói e o herói representado. É a partir dessa perspectiva que podemos interpretar um fragmento cômico de Aristófanes, no qual se lê: "Como Calípides eu sento no chão e limpo o assoalho" (Aristófanes apud Csapo, 2008, p.149). Calípides tensiona a representação dos heróis ao empregar gestos de classes mais baixas em sua atuação e, nesse sentido, desafia o domínio dos próprios poetas sobre a totalidade do espetáculo da tragédia grega antiga.

A partir dessa compreensão, cumpre evocarmos uma outra anedota, extraída de fragmentos de A vida de Sófocles, baseada em testemunhos de biógrafos do século III a.C., segundo a qual Calípides matou Sófocles: "Istros [...] e Neantes [...] dizem que Sófocles morreu desta forma: Calípides [...] enviou-lhe um cacho de 
uvas. Sófocles colocou uma uva verde na boca e, devido à idade avançada, sufocou e morreu." (Vida apud Tyrell, 2004, p.15)13. Diversas interpretações podem ser extraídas dessa anedota. Aqui nos interessa interpretá-la do ponto de vista das transformações pelas quais passou o sistema de produção da espetacularidade trágica grega antiga na passagem do século $V$ a.C. para o século IV a.C., que pode ser compreendida também como a passagem do domínio dos poetas para o domínio dos atores. Sófocles, um poeta de grande prestígio, morreu engasgado com uma uva verde enviada por Calípides, um ator vulgar da nova geração. Essa imagem nos parece ilustrar a aura da reputação que os atores carregaram a partir do momento em que adquiriram o estigma de profissionais remunerados, assim como já acontecia com os auletés, em contraste com a prática cidadã de poetas e coreutas. Estes, voluntários e amadores, competiam em busca da honra, não de recompensas materiais, muito embora as recebessem em abundância.

Persiste, inclusive na tradição dos estudos clássicos, o receio de reconhecer o desenvolvimento econômico da tragédia grega antiga. Csapo (2010) argumenta que isso deriva do fato de que, entre o final do século XIX e o início do século XX, a elite acadêmica dedicada ao estudo de documentos históricos sobre os aspectos materiais do teatro grego antigo encontrava-se em profunda desarmonia com a crescente economização da vida cultural contemporânea. Pickard-Cambridge, por exemplo, que no início do século XX realizou um estudo pioneiro sobre os festivais de teatro de Atenas no século $V$ a.C., parecia relutar em buscar evidências a respeito do valor econômico intrínseco a eles. Isso se justificaria pelo receio de imiscuir a imagem romântica da Grécia clássica com a imagem da indústria cultural nascente em seu tempo.

Na contramão dessa abordagem, Csapo (2010) aponta que já no século V a.C., o financiamento da Grande Dionisíaca combinava recursos públicos, isto é, do Estado, com recursos privados, isto é, de doadores e de investidores. Além disso, é válido notar, que a Grande Dionisíaca instituiu, pela primeira vez na história dos festivais religiosos da Grécia Antiga, uma taxa de admissão. A complexidade desse tipo de financiamento, com suporte de várias fontes, fez com que as produções

${ }^{13}$ Istros [...] and Neanthes [...] say that Sophocles died in this way: Kallippides [...] sent him a cluster of grapes. Sophocles put an unripe grape in his mouth and, because of his advanced age, he choked and died. [Tradução nossa] 
se tornassem cada vez mais orientadas para o público, favorecendo o destaque da atuação na cena e, consequentemente, o processo de profissionalização dos atores trágicos.

Pesquisas recentes também desafiam a abordagem atenocêntrica da tragédia grega antiga, sustentada pela tradição dos estudos clássicos. Nesse sentido, Csapo (2010) aponta que nos últimos cinquenta anos foram encontradas evidências arquitetônicas, epigráficas e literárias de mais de noventa e cinco teatros permanentes, construídos fora das fronteiras de Atenas, datados do final do século IV a.C. Se considerarmos que em Atenas, no século $V$ a.C., as arquibancadas dos teatros eram móveis, podemos depreender que elas também o eram em outras localidades, no mesmo período; de modo que, assim como ocorreu em Atenas, elas teriam sido substituídas por estruturas definitivas de pedra apenas posteriormente. Assim sendo, podemos supor que já no século $V$ a.C. havia apresentações de tragédia em outras localidades da Hélade antiga.

Além disso, para compreendermos a conjuntura complexa que proporcionou a profissionalização dos atores trágicos, devemos considerar que os festivais regulares não eram os únicos espaços para performances teatrais. Slater (2007) argumenta que uma cultura de festivais começou a se desenvolver no final do século V a.C. Surgiram festivais dos mais diversos tipos por toda a Hélade antiga, muitos dos quais contavam com apresentações de modalidades combinadas, de modo que era possível haver competições de tragédia em paralelo com competições atléticas e performances de filósofos, sofistas, excêntricos e charlatões. Havia festivais públicos e privados, locais e pan-helênicos, efêmeros e duradouros, que variavam conforme o calendário. Um festival podia, inclusive, mudar de nome, de status e de propósito.

Em função do entendimento de que havia uma profusão de apresentações de tragédia por todo o mundo grego antigo, Csapo (2010) sugere que há também que se questionar a falácia de que cada tragédia era apresentada uma única vez no contexto de um único festival, como um sacrifício imolado em homenagem a Dioniso para garantir a glória de Atenas. A defesa da ideia de uma performance única de cada tragédia soa como um esforço para negar ou minimizar a dimensão econômica do teatro grego antigo, o que não coaduna com as evidências de que, 
a partir do final do século $V$ a.C., desenvolveu-se um mercado competitivo, graças ao aumento do número de festivais, que favoreceu a profissionalização do ator.

Segundo Csapo (2010), o acontecimento atestado pelas fontes em contrariedade mais evidente à referida falácia é a instituição na Grande Dionisíaca de 386 a.C. de um concurso de reencenação de tragédias antigas; os próprios atores trágicos eram responsáveis por essas produções. Esse fato pode ser compreendido como uma tentativa de Atenas de promover a manutenção do prestígio de seu mais importante festival teatral, frente à proliferação de apresentações de tragédias antigas em festivais menores por todo o mundo grego. Nesse sentido, a data de 386 a.C. não deve ser tomada como um marco inaugural das reencenações, mas como a aceitação e a apropriação por parte de Atenas de um movimento que já vinha acontecendo há algum tempo. Em aderindo às reencenações, Atenas mantinha-se no centro das transformações do fazer teatral, iluminando concomitantemente o trabalho dos atores e o repertório dos poetas.

A proliferação de festivais fora de Atenas e a prática das reencenações forneceram as condições necessárias para o desenvolvimento de um sistema de estrelato no século IV a.C. A demanda por bons atores aumentou com tanta rapidez que rapidamente ultrapassou a oferta. As cidades entravam em negociações para contratar atores especialmente requisitados e ofereciam vantagens financeiras para recebê-los, bem como impunham sanções àqueles que rompessem seus contratos. Até mesmo na Grande Dionisíaca passou-se a ser necessário garantir a presença dos atores por meio do pagamento de taxas de aparição, do oferecimento de grandes adiantamentos e da imposição de multas por não comparecimento. De modo que Csapo (2010) argumenta que mesmo Atenas precisava promover ativamente seu teatro na segunda metade do século IV a.C., devido à competição imposta por outras cidades. Havia oportunidades de trabalho suficientes para os atores e eles poderiam executar seus ofícios sem precisar nem mesmo ir muito longe:

De fato, oportunidades de emprego em número suficiente para permitir a um ator o poder de recusa parecem-me ser a condição necessária para o desenvolvimento da profissão de ator em nosso sentido moderno do termo, com o qual quero dizer um emprego a partir do qual uma pessoa 
consegue viver sem nenhum outro meio de sustento (Csapo, 2010, p.89) ${ }^{14}$.

Segundo Easterling (2008), a função simbólica dos atores cresce à medida que eles passam a ser mais e mais requisitados e, consequentemente, passam a receber vultosas quantias de dinheiro. Eles tornam-se uma categoria profissional desejável de se ter por perto, o que é comprovado pelas fontes, que são unânimes em associar os atores mais importantes ao patrocínio dos poderosos. Nesse sentido, Hall (2008) aponta que profissionais itinerantes, se bem-sucedidos em competições, podiam desfrutar de enormes ganhos e fama, bem como podiam ser honrados com estátuas e direitos civis nas cidades onde atuavam.

Segundo Hall (2008), dada a dificuldade de viajar com grandes grupos, os atores passaram, cada vez mais, a se especializar em determinadas canções de várias tragédias antigas, com destaque para aquelas entoadas por personagens na função de mensageiros, que, em geral, envolviam momentos de grande tensão emocional, nos quais os atores poderiam demonstrar toda a sua virtuosidade. Eles se apresentavam com essas performances individuais em diversos festivais e até mesmo em banquetes.

Um dos atores que mais gozou de prestígio nesse período foi Neoptólemo. Ele foi um dos maiores vencedores dos concursos de reencenação, na Grande Dionisíaca, e conquistou amigos influentes, dentre os quais Filipe II, da Macedônia, de modo que Easterling (1997) argumenta que:

Além de ilustrar a possibilidade dos atores adquirirem riqueza e influência, conjuntamente à sua fama, algumas das epigrafias sobre Neoptólemo carregam grande interesse simbólico, trazendo à tona analogias particularmente próximas entre o poder político e o poder teatral, bem como a forma como o drama e a vida, particularmente a vida de pessoas famosas, parecia interagir e moldar um ao outro (Easterling, 1997, p.217). ${ }^{15}$

\footnotetext{
${ }^{14}$ Indeed, employment opportunities in a number sufficient to allow an actor the power of refusal seem to me to be the necessary condition for the development of an actor's profession in our modern sense of the term, by which I mean an employment from which a person can receive a livelihood without any other means of support. [Tradução nossa]

${ }^{15}$ As well as illustrating the scope for actors to acquire wealth and influence along with their fame, some of the stones told about Neoptolemus have great symbolic interest, bringing out the particularly close analogies between theatrical and political power and the way in which drama and life, particularly the lives of famous people, were felt to interact and to shape one another. [Tradução nossa]
} 
Easterling (1997) evoca um relato que consta na Biblioteca Histórica de Diodoro a fim justificar seu argumento. Segundo Diodoro, Neoptólemo foi convidado para participar do festival em honra ao casamento da filha de Filipe II, da Macedônia, Cleópatra, em 336 a.C., quando este já havia começado os preparativos para a campanha militar contras os persas e:

[...] no banquete real, Filipe ordenou aos tragoidós Neoptólemo, que se destacava por seu poder vocal e popularidade, que executasse algumas peças de sucesso de seu repertório, particularmente qualquer coisa relevante para a campanha contra os persas [...]. Neoptólemo escolheu uma peça que ele pensou que seria considerada apropriada para a travessia de Filipe [para a Ásia]; ele tinha em mente diminuir a riqueza do rei persa e sugerir que, embora agora fosse notoriamente vasta, o acaso poderia destruí-la um dia. [...] Filipe ficou encantado com o que foi dito e totalmente absorvido pela ideia de sua relevância para a derrota do rei persa (Diodoro apud Easterling, p.216). ${ }^{16}$

Desta feita, Diodoro conta como, no dia seguinte, antes de terem início as apresentações, Filipe, convencido de sua relevância pelo canto de Neoptólemo, preparou uma procissão majestosa para sua entrada no teatro. Esta incluía estátuas dos doze deuses do Olimpo, adornadas com materiais muito ricos e, junto a elas, uma décima terceira estátua, representando o próprio Filipe e:

Quando o teatro estava lotado, Filipe entrou vestindo uma capa branca; ele dera ordens ao seu guarda-costas para recuar e seguir à distância, ansioso por demonstrar ao público que era protegido pela boa vontade de todos os gregos e que não precisava de guarda-costas. No auge de seu sucesso, quando todos o elogiavam e o parabenizavam, o inesperado aconteceu: a revelação de um complô totalmente imprevisto contra o rei, um complô que significava a morte (Diodoro apud Easterling, p.217). ${ }^{17}$

Filipe foi apunhalado até a morte. Segundo Easterling (1997), na tentativa de representar no teatro o papel de amado líder dos gregos, Filipe tornou-se

\footnotetext{
${ }^{16}[. .$.$] at the royal banquet Philip ordered the tragoidós Neoptolemus, outstanding for his vocal power and$ popularity, to perform some successful pieces from his repertoire, particularly anything relevant to the campaign against the Persians [...]. Neoptolemus chose a piece which he thought would be taken as appropriate to Philip's crossing [to Asia [...] Philip was delighted with what it said and was totally absorbed by the idea of its relevance to the defeat of the Persian king. [Tradução nossa]

17 When the theatre was full Philip came in wearing a white cloak; he had given orders to his bodyguard to stand back and follow at a distance, eager to demonstrate to the public that he was protected by the goodwill of all the Greeks and had no need of a bodyguard. At such a high point in his success, when everyone was praising and congratulating him, the unexpected happened: the revelation of a completely unforeseen plot against the king, a plot that meant death. [Tradução nossa]
} 
protagonista de sua própria tragédia. O canto entoado por Neoptólemo como uma previsão lisonjeira do poder de Filipe torna-se, pois, uma previsão real, porém invertida, de modo a representar como as fronteiras entre teatro e vida eram tênues no final do século IV a.C. Em uma passagem do Florilégio de João Estobeu, redigida muitos séculos depois desse acontecimento, consta uma resposta de Neoptólemo à pergunta sobre o que ele mais admirava nas obras de Ésquilo, Sófocles e Eurípides: "Nada deles, mas o que ele próprio testemunhou em um palco maior: Filipe, em procissão no casamento de sua filha, Cleópatra, aclamado como décimo terceiro deus, e no dia seguinte assassinado no teatro" (Estobeu apud Easterling, 1997, p.219) ${ }^{18}$. A compreensão de que a morte de Filipe II foi o maior ato trágico testemunhado pelo grande ator Neoptólemo é paradigmática do sistema de produção da espetacularidade trágica no final do século IV a.C, de modo que podemos considerar, em conformidade com Chaniotis (1997), que "a percepção da vida como um drama e a difusão de outras formas dramáticas no pensamento grego estão diretamente relacionadas à crescente popularidade das performances teatrais" (Chaniotis, 1997, p. 220).19

Após a morte de Felipe II, seu filho, Alexandre III, assumiu o comando do reino da Macedônia e expandiu consideravelmente as suas fronteiras, consolidando um dos mais vastos impérios da antiguidade e recebendo a alcunha de "o Grande". Nesse contexto, a cultura grega antiga difundiu-se por toda a extensão do Império da Macedônia que, após 323 a.C. com a morte de Alexandre, o Grande, fragmentouse em numerosos reinos governados pelas linhagens dos generais do antigo imperador. Nesse contexto, a tragédia grega antiga adquire ares ainda mais cosmopolitas e nota-se, ao longo do século III a.C., um aumento significativo no número de festivais em todo o mundo helenístico. Segundo Aneziri (2009), os reis helenísticos tentavam emular a figura de Alexandre, o Grande através da criação de festivais que colocassem lado a lado o culto dos reis e o culto de Dioniso, o que Chaniotis (1997) percebe como uma tentativa de dionisação da personalidade

\footnotetext{
18 Not anything of theirs, but what he himself had witnessed on a greater stage: Philip in procession at the wedding of his daughter Cleopatra and hailed as thirteenth god, and the next day murdered in the theatre and thrown out. [Tradução nossa]

${ }^{19}$ the perception of life as a drama and the diffusion of other dramatic similes in Greek thought are directly related to the increasing popularity of theatrical performances. [Tradução nossa]
} 
dos reis

Com o aumento significativo do número de festivais, distribuídos em uma vasta extensão geográfica, tornou-se cada vez mais complicado organizá-los com sucesso. Era difícil atender a logística das exigências básicas de um festival, como a presença de ao menos dois competidores por evento, por exemplo. Frequentemente os festivais coincidiam em data e era impossível que essa organização fosse feita apenas por profissionais locais, de modo que os reis tinham que recorrer à colaboração de profissionais estrangeiros de diferentes especialidades. Grupos inteiros viajavam por toda a extensão do mundo helenístico; eles ensaiavam no local em que estavam estabelecidos e provavelmente continuavam os preparativos para a performance no local em que se apresentariam.

É nesse contexto que surgem associações que reuniam profissionais que se apresentavam em festivais. Segundo Aneziri (2020) os profissionais de música e teatro começaram a formar associações com o nome de "os artistas (technîtai) de Dioniso", uma vez que colocavam sua arte a serviço dessa divindade e assim consideravam que estavam sob sua proteção. Apesar de representantes de muitas outras categorias profissionais viajarem longas distâncias durante o período helenístico, é digno de nota que os artistas da cena tenham sido os primeiros profissionais a criarem uma associação, uma vez que sua atividade envolvia, prioritariamente, uma realização coletiva. Possivelmente, esses profissionais eram descritos como artistas de Dioniso ainda no século IV a.C., mas a sua organização em associações expressa uma forma de se fazer teatro muito característica da passagem para o século III a.C. e adiante.

Essas associações de artistas de Dioniso se multiplicaram numericamente por todo o mundo helenístico. Em geral elas recebiam o nome de koinon. Dentre aquelas que se destacaram, Aneziri (2020, p.296) aponta:

A associação de Atenas foi uma das quatro maiores desse tipo a surgir no século III a.C. As outras três eram: (1) a associação dos artistas de Dioniso que viajaram juntos/contribuíram para Istmo e Nemea [...], que tinha filiais em várias partes da Grécia continental (mas não na Ática); (2) a associação de artistas (que eram ativos) em ou (que viajaram) para Jônia e a região de Helesponto [...] e que depois de 188 a.C. juntou-se com os technithai devotos de Dioniso Kathegemon [...]; e (3) a associação de 
artistas com base no Egito [...], que mais tarde adquiriu uma filial em Chipre. ${ }^{20}$

Aneziri (2007) argumenta que um festival poderia ser organizado por um rei, por uma associação ou pela junção dos esforços de ambos. Sem embargo, as associações eram o ponto de contato fundamental entre os artistas e seus futuros empregadores. O prestígio e o esplendor dos festivais eram em grande parte medidos por seu poder de atrair participantes de várias regiões do mundo helenístico. Uma vez que as associações tinham braços em diversos territórios, bem como seus membros incluíam artistas de diferentes cidades e regiões, o envio de artistas de uma associação para um determinado festival atendia geralmente à demanda por participantes de diversas etnias.

As associações eram também fundamentais para garantir segurança nas longas viagens que os artistas deveriam fazer. Os festivais nunca perderam seu caráter cívico-ritual, de modo que as associações representavam a conjunção entre a profissionalização dos artistas e a manutenção das características sagradas de seu ofício. Assim sendo, seus membros devem ser considerados profissionais a serviço de Dioniso. Em suas viagens por caminhos cujo perigo de pirataria e banditismo era iminente, aos artistas de Dioniso era dada a possibilidade de se albergarem em santuários, espaços sagrados que, desde o período arcaico, eram tidos como invioláveis. "A adesão a uma associação e os privilégios básicos de inviolabilidade, segurança e imunidade que a acompanhava proporcionavam aos artistas um passaporte que facilitava a sua circulação." (Aneziri, 2009, p. 233)21. Podemos justificar o emprego do termo "passaporte" se considerarmos que ser membro de uma associação oferecia um status legal e social privilegiado.

Além disso, se considerarmos que os artistas não eram necessariamente cidadãos da localidade em que a associação a que pertenciam tinha a sua sede,

${ }^{20}$ The association of Athens was one of the four largest of this kind to appear in the third century. The other three were: (1) the association of artists of Dionysus who travelled together/contributed towards the Isthmus and Nemea [...], which had branches in various parts of mainland Greece (but not Attica); (2) the association of artists (who were active) in or (who travelled) to lonia and the Hellespontine region [...] and after $188 \mathrm{BC}$ joined with the technitai devoted to Dionysus Kathegemon [...]; and (3) the association of artists based in Egypt, [...] which later acquired a branch in Cyprus. [Tradução nossa]

${ }^{21}$ Membership of an association and the basic privileges of inviolability, security and immunity that accompanied it thus provided the artists with a passport that facilitated their movement. [Tradução nossa] 
poderemos perceber a especial importância da filiação. As associações trocavam correspondências com cidades e reis de todo o mundo helenístico, bem como enviavam seus próprios embaixadores aos festivais. Elas tinham características de e funcionavam como um Estado, de modo que Aneziri (2009) sugere que a filiação a uma associação correspondia, de certa maneira, à cidadania.

Um exemplo bastante ilustrativo dessa relevância das associações para a prática dos artistas no período helenístico é apresentado por Le Guen (2007). A autora tenta reconstituir, a partir da análise de documentos históricos, a história de Cráton, um tocador de aulós que viveu no século II a.C. e que integrou a associação dos artistas de Dioniso da Ásia Menor. Há cerca de dez evidências epigráficas sobre ele, o que o torna o tocador de aulós da antiguidade de que temos mais informações documentadas. As fontes, em sua maioria, referem-se a ele como auletés, sem qualquer qualificação adicional; com exceção de uma, em que ele aparece como um auleteés cíclico, isto é, um tocador de aulós que se apresentava acompanhado por um coro ditirâmbico.

Segundo Le Guen (2007), em citando Bélis (1999), "o status social dos músicos não era inerente aos instrumentos que eles tocavam, mas às atividades que eles exerciam" (Bélis apud Le Guen, 2007, p.252) 22. Nesse sentido, apesar de os tocadores de aulós geralmente ocuparem a base da escala social, isso não deve ser entendido como uma universalidade; dentre aqueles que podemos citar como ocupando essa baixa posição, estão, por exemplo, aqueles que exerciam sua atividade profissional em navios de guerra e em cerimônias fúnebres. Cráton, por sua vez, gozou de um surpreendente respeito durante a sua vida, de sorte que há evidências que indicam que ele tenha exercido em algumas ocasiões as funções de agonothetes (isto é, de organizador de festivais), de sacerdote de Dioniso e de embaixador de associações, o que contraria em muito aquela posição social que os auletai costumavam ocupar no século V a.C em Atenas.

As fontes não indicam, contudo, qual o valor de seus honorários nem a forma como exerceu sua profissão. Não se sabe em qual gênero musical se destacou, nem mesmo qual era o tipo de aulós, dentre os muitos existentes, que ele tocava.

22 the social status held by musicians was not inherent in the instruments they played but in the activities they pursued [Tradução nossa] 
Não obstante, embora não haja evidências relativas à conexão entre a respeitada posição social de Cráton e seu status como artista, de modo que seu trabalho fosse generosamente remunerado, as fontes indicam por unanimidade que ele foi um homem rico, apesar de não confirmarem a origem de sua fortuna.

Evocamos aqui a imagem de Cráton não apenas em função de seu sucesso individual, mas sobretudo porque, segundo Le Guen (2007), sua vida foi inteiramente devotada às associações de artistas de Dioniso.

A primeira associação de que se tem registro de que Cráton esteve conectado foi o koinon dos sinagonistas, que reunia artistas de diferentes especialidades que participavam de festivais, mas não tinham permissão para concorrer a qualquer prêmio.

Cráton também foi membro do koinon da Jônia e de Helesponto, com base na cidade de Teos, que em 188 a.C. uniu-se ao koinon de Dioniso Kathegemon, com base na cidade de Pérgamo, governada pela dinastia Atálida. Essa união deu origem ao que Le Guen (2007) denomina Associação dos Artistas da Anatólia. Como agradecimento ao rei Eumenes II por ter permitido a criação da Associação dos Artistas da Anatólia, Cráton cria o koinon dos Atálidas em sua homenagem.

A importância de Cráton a frente dessas Associações garantiu-lhe todo o tipo de recompensa: elogios públicos, inscrições comemorativas, coroas, estátuas etc. Dentre todas essas homenagens, cumpre destacar uma em especial: a estátua erigida na cidade de Teos, ao lado da qual foi instalado um tripé e um incensário em que o sacerdote do rei deveria queimar incensos durante as festividades dadas por Eumenes II. Sobre essa estátua Le Guen (2007, p.271) pontua:

Mesmo que, no caso de Cráton, a estátua para a qual o incensário deve ser usado seja descrita como uma andrias (como é usual para estátuas honoríficas) e não um agalma (usado apenas para estátuas de culto), as semelhanças que se desenvolvem entre suas práticas mostram até que ponto a fronteira entre privilégios honoríficos e honras de culto se tornou confusa. Enquanto ele ainda estava vivo, os contemporâneos de Cráton o viam como um homem excepcional, de um status próximo ao dos deuses, heróis ou dos mortos, para quem grandes quantidades de incenso e outros perfumes foram queimado. ${ }^{23}$

${ }^{23}$ Even though in the case of Kraton the statue for which the censer is to be used is described as an andrias (as is usual for honorific statues) and not an agalma (used only of cult statues),113 the similar- ities that 
À vista disso, Le Guen (2007) argumenta que Cráton não foi simplesmente um benfeitor, mas que sua história ilumina não apenas o papel desempenhado pelas Associações de Artistas de Dioniso na prática de difusão dos cultos reais, mas também a maneira pela qual os soberanos se comportavam diante dos artistas e de seus próprios reinos.

Para suprir o intenso desejo de dionisação dos reis helenísticos, não bastava apenas que eles se aproximassem da imagem de Alexandre, o Grande, nem que apenas favorecessem o culto de Dioniso. Era necessário que eles reforçassem o teatro como espaço da prática cívico-ritual, colocando lado a lado o culto dos reis e o culto de Dioniso. Cráton e sua atividade frente ao koinon dos Atálidas é a expressão máxima desse propósito. Ele era o mais dionisíaco dos artistas porque o som do aulós era o som de Dioniso.

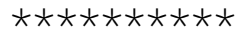

Buscamos dispor imagens para uma compreensão histórica dos mistérios de duas profissões que carregavam, ao mesmo tempo, os signos e as sensibilidades da festa, do culto e da itinerância. Buscamos acompanhar os passos dos artistas de Dioniso, viajando por terras que iam muito além daquelas que os pés poderiam pisar.

Ao som do aulós, atores trágicos cantavam o estertor dos heróis e o alvorecer de uma profissão.

\section{Referências}

ANEZIRI, Sophia. Artists of Dionysus: The first professional associations in the ancient Greek world. In HARRIS, Edward, LEWIS, David, STEWART, Edmund (org.). skilled labour and professionalism in ancient Greece and Rome. Cambridge: Cambridge University Press, 2020, p.293-312.

ANEZIRI, Sophia. The organisation of music contests in the hellenistic period and artists' participation: An Attempt at Classification. In: WILSON, Peter (org.). The Greek theatre and festivals: documentary studies. Oxford. Oxford University Press, 
2007, p.67-84.

ANEZIRI, Sophia. World travellers: the associations of artists of Dionysus. In: HUNTER, Richard, RUTHERFORD, lan (org.) Wandering poets in ancient Greek culture: travel, locality and pan-hellenism. Cambridge: Cambridge University Press, 2009, p.217-236.

ARISTÓTELES. Poética. Lisboa: Fundação Calouste Gulbenkian, 2008.

BÉLIS, Annie. Les musiciens dans l'antiquité. Paris: Hachette Littératures, 1999.

CHANIOTIS, Angelos. Theatricality beyond the theater: staging public life in the hellenistic world. Pallas: revue d'études antiques, Paris, v. 47, n. 1, p. 219-259, 1997.

CSAPO, Eric. Actors and icons of the ancient theatre. Oxford: Wiley-Blackwell, 2010.

CSAPO, Eric. Calípides limpando o assoalho: os limites do realismo no estilo clássico de atuação e interpretação. In: EASTERLING, Pat, HALL, Edith (org.). Atores gregos e romanos: aspectos de uma antiga profissão. São Paulo: Odysseus, 2008, p.145-170.

EASTERLING, Pat. From repertoire to canon. In: EASTERLING, Pat (org.). The Cambridge companion to Greek tragedy. Cambridge: Cambridge University Press, 1997, p.211-227.

EASTERLING, Pat. O ator como ícone. In: EASTERLING, Pat, HALL, Edith (org.). Atores gregos e romanos: aspectos de uma antiga profissão. São Paulo: Odysseus, 2008, p.383-400.

HALL, Edith. Atores-cantores da antiguidade. In: EASTERLING, Pat, HALL, Edith (org.). Atores gregos e romanos: aspectos de uma antiga profissão. São Paulo: Odysseus, 2008, p.3-44.

HERINGTON, John. Poetry into drama: early tragedy \& the Greek poetic tradition. Berkeley: University of California Press, 1985.

KOVACS, George. Stringed instruments in fifth-century drama. In: HARRISON, George William Mallory, LIAPIS, Vayos (org.). Performance in Greek and Roman theatre. Boston: Brill, 2013. p.477-500.

LE GUEN, Brigitte. Kraton, Son of Zotichos: Artists' Associations and Monarchic Power in the Hellenistic Period. In: WILSON, Peter (org.). The Greek theatre and festivals: documentary studies. Oxford. Oxford University Press, 2007, p.246-278.

MEINECK, Peter. Under Athena's gaze: Aeschylus' Eumenides and the topography of opsis. In: HARRISON, George William Mallory, LIAPIS, Vayos (org.). Performance in Greek and Roman theatre. Boston: Brill, 2013. p.161-180.

MOTA, Marcus. A dramaturgia musical de Ésquilo: investigações sobre composição, 
realização e recepção de ficção audiovisual. Brasília: Editora UnB, 2008.

PICKARD-CAMBRIDGE, Sir Arthur Wallace. The dramatic festivals of Athens. Oxford: Oxford University Press, 1968.

RAMOS, Luiz Fernando. Mimesis performativa: a margem de invenção possível. São Paulo: Annablume, 2015.

SCHECHNER, Richard. Performance theory. Londres: Taylor \& Francis, 1988.

SLATER, William. Deconstructing festivals. In: WILSON, Peter (org.). The Greek theatre and festivals: documentary studies. Oxford. Oxford University Press, 2007. p.21-47.

SUTTON, Dana Ferrington. The theatrical families of Athens. The American Journal of Philology, Cambridge, v. 108, n. 1, p.9-26, 1987.

TYRELL, Blake. The Suda's Life of Sophocles (sigma 815): translation and commentary with sources. Electronic Antiquity, Blacksburg, v. 9, n. 1, p.1-231, 2004.

WILSON, Peter. Music. In: GREGORY, Justina (org.). A companion to Greek tragedy. Oxford: Blackwell Publishing, 2005. p.183-193.

WILSON, Peter. Os músicos entre os atores. In: EASTERLING, Pat, HALL, Edith (org.). Atores gregos e romanos: aspectos de uma antiga profissão. São Paulo: Odysseus, 2008. p.45-78.

Recebido em: 15/06/2021

Aprovado em: 12/08/2021 